\title{
Haematological Parameters and Histomorphological Effect of Varied Parts of Citrullus Lanatus Juice Fed to Adult Female Mice
}

\author{
${ }^{1}$ IWALAYE, OA; *2EKUNDINA, VO; ${ }^{1}$ ONI, A \\ ${ }^{1}$ Department Of Zoology and Environmental Biology, Ekiti State University, Ado-Ekiti, Ekiti State, Nigeria \\ ${ }^{* 2}$ Department of Medical Laboratory Science, Afe-Babalola University, Ado-Ekiti, Ekiti State, Nigeria \\ *Corresponding Author Email: ekundinav@abuad.edu.ng; Tel: +2348038836691
}

\begin{abstract}
Plants basically will continue to be the starting materials in making modern drugs. As a result of this, many believe in using herbal products than convectional drugs because of their easy accessibility, low side effects and affordability. Citrulluslanatus (popularly known as watermelon) is a citrus fruit known to contain among others, citrulline and lycopene with hepatoprotective actions on organs such as liver and kidney because of it bioactive and antioxidant properties. This study investigates the haemathological parameters and histopathological effects of crude C. lanatus juice on the liver and kidney of mice. Twenty five female mice weighing between $72-99 \mathrm{~g}$ were randomly divided into five groups (A - E) of five mice each. Group A, were given water (control); group B, were given $2 \mathrm{ml}$ of watermelon flesh juice; group $\mathrm{C}$, were given $2 \mathrm{ml}$ of watermelon flesh and seed juice, group $\mathrm{D}$, were given $2 \mathrm{ml}$ of watermelon flesh and rind juice; and group $\mathrm{E}$ were given $2 \mathrm{ml}$ ofwatermelon flesh, seed and rind juice once daily for four weeks. At the end of experiment, animals were sacrificed and dissected. Blood sample were taken through cardiac puncture, liver and kidney tissue were excised also to determine the haematological and histopathological effects using routine diagnostic techniques. Highest blood and differential counts except WBC were obtained in groups exposed to crude C. lanatus juice when compared with the control.The liver of animals in all groups appears normal with no remarkable differences from the control. Also, no remarkable differences were recorded in the kidney of animals in all groups except group $\mathrm{E}$ which showed interstitial edema with some renal tubules within the cortex undergoing degeneration. From this study and at the dose and duration of study, every part of C. lanatushad no negative impact on the histopathology of the liver and kidney and also had the potential to boost the immune system.
\end{abstract}

\section{DOI: https://dx.doi.org/10.4314/jasem.v24i11.16}

Copyright: Copyright $($ C 2020 Iwalaye et al. This is an open access article distributed under the Creative Commons Attribution License (CCL), which permits unrestricted use, distribution, and reproduction in any medium, provided the original work is properly cited.

Dates: Received: 25 January 2020; Revised: 05 November 2020; Accepted: 14 November 2020

Keywords: Citrullus lanatus, haematology, histopathology, kidney, liver, mice

Plants as nature gift has over centuries played a fundamental role in the development of modern human medicine as they constitute the active compounds in modern day drugs. Plant medicine (phytoamedicine) has been used in healthcare delivery in many parts of Africa and the rest of the world (Elujoba et al., 2005).Report showed that most people $(80 \%)$ in developing countries depend on plant medicine for their healthcare (Sofowora, 1993, Oyewo et al., 2012).Effective health cannot be achieved in Africa, unless orthodox medicine is complemented with traditional medicine (Elujoba et al., 2005). Thus, the interest of many people around the world is gradually shifting towards fruits and vegetables because of theirtherapeutic benefits, economical values and easy accessibility. Watermelon (Citrullus lanatus) have become a welcome fruit for many Africans because of it affordability among others thus, its cultivation has greatly increased in many African Countries to meet peoples demand. According to Erhirhieand Ekene, (2013), watermelon is one of the fruit that is wildly used in traditional herbal medicine.
Different literatures reveal the richness of watermelon in phyto-constituents such as calcium, dietary fiber, flavonoids, iron, magnesium, phosphorus, potassium, vitamins andzinc (Oyewo et al., 2012; Adesanya et al., 2011). Watermelon has been reported to contain carotenoids ( $\beta$-carotene), including lycopene which has a protective effect through its antioxidant properties (Adesanya et al., (2011); Kolawole and Dapper, (2016) thereby inactivating the reactive oxygen species (ROS) and reducing the free radicals (Yilmaz et al., 2015).More so, water melon has been used for treating urinary tract infection, bed wetting, dropsy, renal stones, alcohol poisoning, hypertension, diabetic, diarrhea and gonorrhea (Elujobaet al., 2005;Erhirhie and Ekene, 2013; Jiyun et al., 2011 and Figueroa et al., 2012).C. lanatus had been reported as one major fruits that is excessively consumed in Nigeria which tended to produce no severe health effects, Ekundina et al., (2015) but most people avoid eating the seed and rind due to their unappealing flavor. Hence, this study aimed at accessing the 
histomorphological effects of varied part of crude $C$. lanatus on the liver and kidney of female mice.

\section{MATERIALS AND METHODS}

Experimental Animals: Twenty five female rat weighing between 72- $99 \mathrm{~g}$ were used for the experiment. Animals were obtained from the Department of Pharmacy, Obafemi Awolowo University, Ile-Ife, Osun State, Nigeria and were immediately transported to Ekiti State University in cages that provided them with feed and water. The mice were kept in cages and maintained under12hrs day and night cyclein a cross- ventilated animal house. They were acclimatized for two weeks and allowed free access to vital feed purchased from a shop opposite Okesa market in Ado- Ekiti and water given ad libitum. Animal housing, handling and welfare as obtained from The United States National Institute of Health (NIH) Guide for Care and Use of Laboratory Animals were strictly followed throughout the period of experiment to ensure animals are in good condition.

Experimental design: Animals were weighed and have their weight recorded after which they were randomly divided into five groups (A - E) with each consisting five mice. Crude $C$. lanatus juice was administered to animals once daily by oral gavage for four weeks as follows:

Group A: Control (water)

Group B: $2 \mathrm{ml} / \mathrm{kg}$ (water melon flesh)

Group C: $2 \mathrm{ml} / \mathrm{kg}$ (water melon flesh and seed)

Group D: $2 \mathrm{ml} / \mathrm{kg}$ (water melon flesh and rind)

Group E: $2 \mathrm{ml} / \mathrm{kg}$ (water melon flesh, seed and rind)

Crude $C$. lanatus juice was given to the animals once daily for four weeks

Plant Materials and Preparation of crude extracts: Fresh fruits of $C$. lanatus were obtained from Oja Oba market in Ado- Ekiti, Ekiti State, Nigeria. Fruit was identified and authenticated by a plant taxonomist from Department of Plant Science, Faculty of Science, Ekiti State University, AdoEkiti, Ekiti State, Nigeria. It was thoroughly washed, sliced and divided into various parts as designed. This was poured into electric blender and were blended separately (no water added) until a fine solution was obtained. This was given to the mice accordingly.

Determination of weight gain: The weight was taken to the nearest $(0.1 \mathrm{~g})$ once in a week with weighing balance. The weight gained in mice at the end of the experiment was determined by subtracting the mean final from mean initial.
Preparation of Animal: At the end of experiment, each mouse was anaesthetized in a chloroform saturated chamber. Animal was dissected through abdominal opening, blood samples were collected through cardiac puncture and were immediately placed in anticoagulated bottles and were taken to the laboratory for further analysis. The liver and kidney tissues were excised promptly from the sacrificed animals (Motshkeri et al., 2014) Tissues were rinsed in normal saline, placed in a tissue cassette and thereafter fixed with 10\% formal saline and thereafter processed to obtained routine histopathological examinations.

Determination of $C$. lanatus Proximate Composition: C. lanatus proximate composition was determined using standard analytical procedures at the Central Science Laboratory at Federal University of Technology Akure (FUTA), Ondo State, Nigeria.

\section{RESULTS AND DISCUSSION}

The result of the proximate composition of $C$. lanatus is shown in table 1 . The flesh had the highest moisture content $(57.70 \%)$ and carbohydrates $(28.74 \%)$ while it contained the least ash content, crude fibre, crude protein and fat content with the following figures $2.27 \%, 3.77 \%, 3.96 \%$ and $3.56 \%$ respectively. The seed had the highest crude protein $(5.57 \%)$ and fat content $(17.87)$ and the rind had the highest crude fibre $(17.16 \%)$. The mean weight gained in mice is shown in Table 2. The highest weight gain was recorded in group $\mathrm{C}$ followed by group $\mathrm{B}, \mathrm{D}, \mathrm{A}$ and $\mathrm{E}$ with the following figures $34.40,28.30,25.00,18.50$ and 17.40 respectively. Table 3 showed some of haematological and differentials count of the experimental mice. Group $D$ had the highest value in PVC (29.4) and Neutrophils (50\%). The least values $22.4,2260 \mathrm{~mm}^{3}$, $41.8 \%, 39.8 \%, 5.4 \%$ and $2.0 \%$ was recorded in group E for PVC, WBC, Neutrophils, Lymphocytes and monocytes respectively.

Group A had the highest white blood cell (7800) and the highest value (45.0 and 3.8) was recorded in group B for lymphocytes and eosinophils respectively. The highest value (8.2) was recorded in group $\mathrm{C}$ for monocytes. The result of the liver histopathology of the control and experimental mice is shown in figures 1 to 5 . Fruits play an important role in human nutrition and health (Wargovich, 2000) thus has historically held a place in dietary guidance because of their concentrations of vitamins, folic acid, thiamine, niacin, pyridoxine, dietary fibre, minerals especially electrolytes; and more recently phytochemicals, especially antioxidants. 
Table 1: The proximate composition of C. lanatus flesh, seed and rind

\begin{tabular}{llll}
\hline Moisture Content & 57.70 & 50.12 & 55.39 \\
Carbohydrate & 28.74 & 14.24 & 13.32 \\
Ash Content & 2.27 & 4.56 & 5.86 \\
Crude Fibre & 3.77 & 7.64 & 17.16 \\
Crude Protein & 3.96 & 5.57 & 3.80 \\
Fat Content & 3.96 & 17.87 & 4.50 \\
Total $(100 \%$ & 100 & 100 & 100 \\
\hline
\end{tabular}

Table 2: The mean weight gained $(\mathrm{g})$ in mice at the end of the experiment

\begin{tabular}{llllll}
\hline & Group A & Group B & Group C & Group D & Group E \\
\hline Initial weight (g) & 87.50 & 72.70 & 79.10 & 74.50 & 98.60 \\
Final weight (g) & 106.00 & 101.00 & 113.50 & 99.50 & 116.00 \\
Weight gained(g) & 18.50 & 28.30 & 34.40 & 25.00 & 17.40 \\
\hline \multicolumn{7}{c}{ Table 3: The Haematology and differentials count of the experimental mice. } \\
\hline \multicolumn{7}{c}{ Group A } & Group B & Group C & Group D & Group E \\
\hline PCV & 27.6 & 25.8 & 28.8 & 29.4 & 22.4 \\
WBC (mm ${ }^{2}$ ) & 7800 & 2760 & 2340 & 2760 & 2260 \\
Neutrophils (\%) & 46.8 & 43.8 & 44.6 & 50.0 & 41.8 \\
Lymphocyte (\%) & 42.2 & 45.0 & 43.6 & 40.6 & 39.8 \\
Monocytes (\%) & 7.0 & 7.4 & 8.2 & 7.4 & 5.4 \\
Eosinophils (\%) & 3.0 & 3.8 & 3.6 & 2.0 & 2.0 \\
\hline
\end{tabular}

The proximate composition showed water melon contains a significant amount of water as highest figures were recorded for moisture contents in all the various parts studied. Sundia (2007) reported that water melon regulate acid/base balance in the body a major property of water. Also, the sweetening taste of $C$. lanatus flesh which made it the most consumed part of the fruit can be attributed to the highest carbohydrate recorded in this part while the unappealing taste of the rind could be as result of low carbohydrate that is present.

The highest crude fibre recorded in C. lanatus rind is an indicator of its necessity in daily diet. C. lanatus was documented to contain fibres most especially, the rind (Kolawole and Dapper, (2016); Tan et al., 2009).

The highest protein recorded in the seed is in agreement with the report made by Oyewo et al., (2012) that water melon seeds are excellent sources of protein. The experimental mice from all groups showed significant weight gain. This result is in agreement with the report made by Oyewo et al., (2012), that there was a significant dose dependent weight gain in male wistar rat after oral administration of $C$. lanatus.

It was demonstrated by El-Aday and Taha, (2001) that $C$. lanatus extract contain nutritive components such as magnesium, calcium, potassium, iron, phosphorus and zinc which could progressively lead to increase in weight.

Ekundina et al., (2015) reported weight gain in adult male wistar that was given aqueous extract of $C$. lanatus. The low weight gain recorded in group D and $\mathrm{E}$ when compared with other experimental group could be as a result of the rind that is low in carbohydrate and high in crude fibre. The highest weight gain recorded in group $\mathrm{C}$ could be attributed to high crude protein contained in seed; which provide the building blocks for growth and repair of all the body cells, including skin cells, liver cells, immune cells, as well as muscle cells, and fat content contained in C. lanatus seed. This is in agreement with the report of Maria et al., (2008) that water melon seeds contain high amount of amino acids. Also, Tang et al., (2009) showed that fatty content of the seeds is highest.

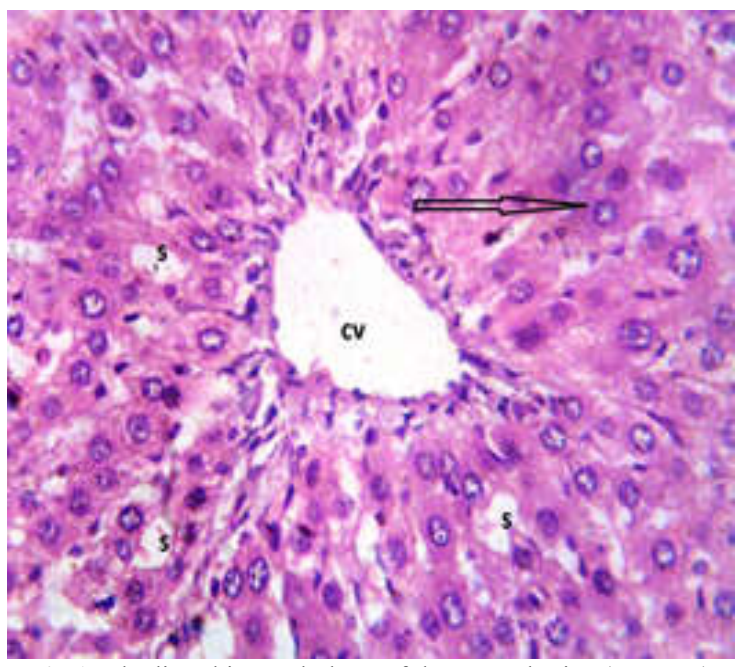

Fig 1: The liver histopathology of the control mice (group A) (Mag. X400 H\&E): Micrograph shows a hepatic tissue with central vein (CV) located at the center of the lobule; hepatocytes (arrow) are disposed in sheet and are separated by the sinusoids

(S). The Interstitium appears essentially unremarkable. 


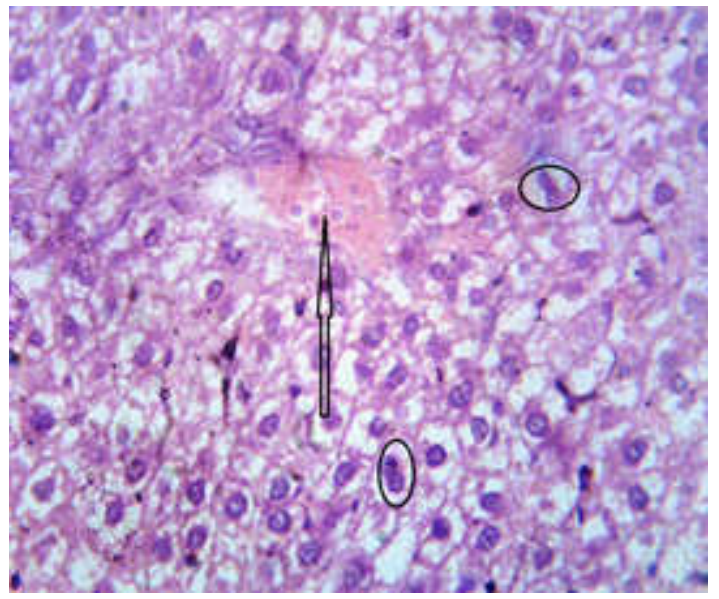

Fig 2: The liver histopathology of experimental mice fed with $C$. lanatus flesh juice (Group B) (Mag. X400 H\&E): Micrograph show congested vessels (arrow), and some hepatocytes (circled) appear binucleated.

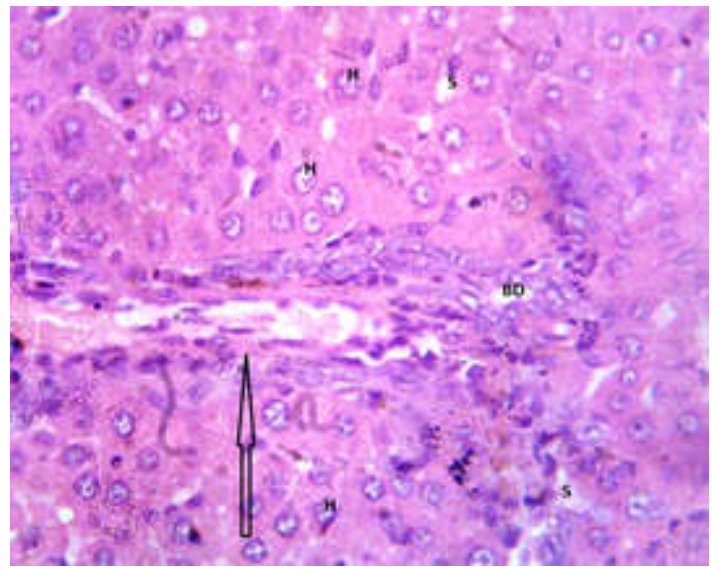

Fig 3: The liver histopathology of experimental mice fed with $C$. lanatus flesh and seed juice (Group C) (Mag. X400 H\&E):

Micrograph shows periportal inflammatory cells (arrow), the hepatocytes $(\mathrm{H})$ and sinusoids $(\mathrm{S})$ appear essentially unremarkable.

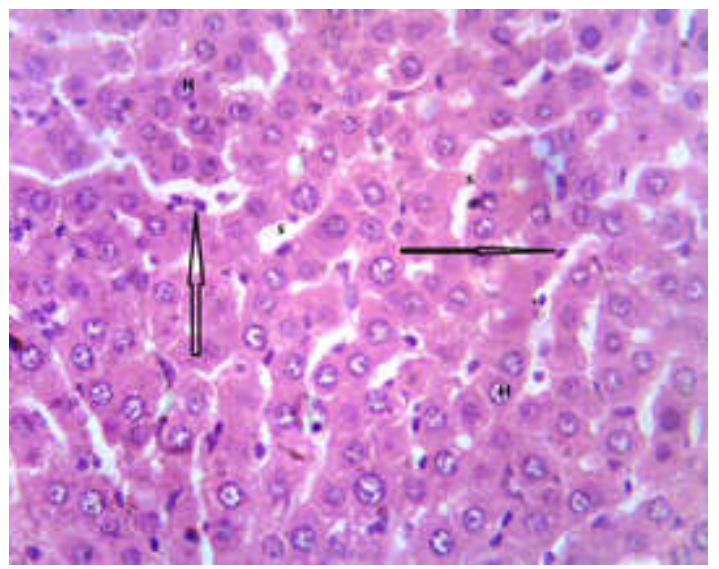

Fig 4: The liver histopathology of experimental mice fed with of C. lanatus flesh and rind juice (Group D) (Mag. X400 H\&E): Micrograph shows marked presence of hepatic macrophage (arrow), the sinusoids (s) appear dilated, however they are free from collections and inflammatory cells.



Fig 5: The liver histopathology of experimental mice fed with $C$. lanatus flesh, seed and rind juice (Group E) (Mag. X400 H\&E). Micrograph shows a liver with periportal inflammatory cells (arrow) mild dilation of the sinusoids (DS) and congested vessels (CO). The vascular channels are free from congestion.

The kidney histopathological results of the experimental animals are shown in figures 6 to 10 . There was a slight increase in packed cell volume (PCV) of groups $\mathrm{C}$ and $\mathrm{D}$ when compared with the control samples, this could be could be an indicator to it nutritional benefits. Reduction in white blood cells count (WBC) was recorded in groups exposed to varying parts of crude C. lanatus juice when compared to the control. Monocytes of group B, C and D were slightly increased when compared with the control while group D and E had the least eosinophils. Though, the variations in these parameters were not statistically tested. The liver histopathology of the control mice showed hepatic tissue with central vein located at the center of the lobule; hepatocytes disposed in sheet, and separated by the sinusoids. The hepatic portal vessel bring to the liver cell, the blood which has previously passed through the intestine and spleen, the hepatocyte are involved in the formation of primary bile. The liver of mice fed with $C$. lanatus flesh, seed and rind showed a mild dilation in the sinusoid and the presence of periportial cells and portal vessel. The congestion and of the inflammatory cells in the vessel is an indicator that C. lanatus juice has the ability to activate the immune system. Iboi and Agoreyo (2013) documented that central venous congestion and periportal inflammation in the liver of wistar rats. Also, it was shown that the liver has no portal cells while it shows the presence of macrophages. Macrophages are cells that mop-up foreign substance that are harmful to the tissue. More so, nucleus and hepatocyte remain normal and free from congestion and inflammatory cell. The liver of the mice fed with C.lanatusflesh and rind juice showed congested vessel and the presence of white blood cell in the liver tissue. This shows that the juice was able to activate the immune system of the liver cell. 




Fig 6: The kidney histopathology of the control mice (Group A) (Mag. X400 H\&E): Micrograph shows a renal corpuscle (black arrow) consisting of the Glomerulus, Bowman's capsule, with a well-defined bowman's space (BS). The renal tubules (RT) are

lined by regular epithelium; the interstitium is free from congestion and inflammatory cell.

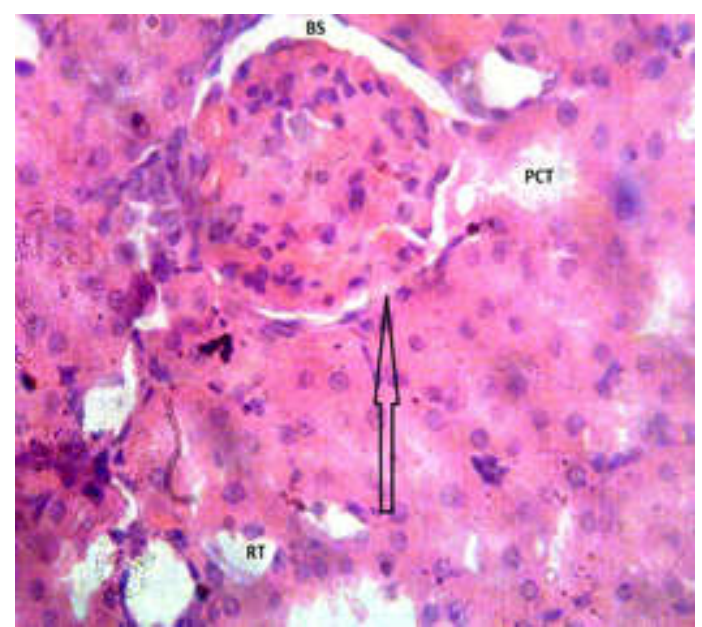

Fig 7: The kidney histopathology of experimental mice fed with C. lanatus flesh juice (Group B) (Mag. X400 H\&E): Micrograph shows a renal corpuscle and a well outlined bowman's space

(BS), the renal tubules (PCT and RT) are essentially not remarkable, the interstitium is free from collections and inflammatory cells.

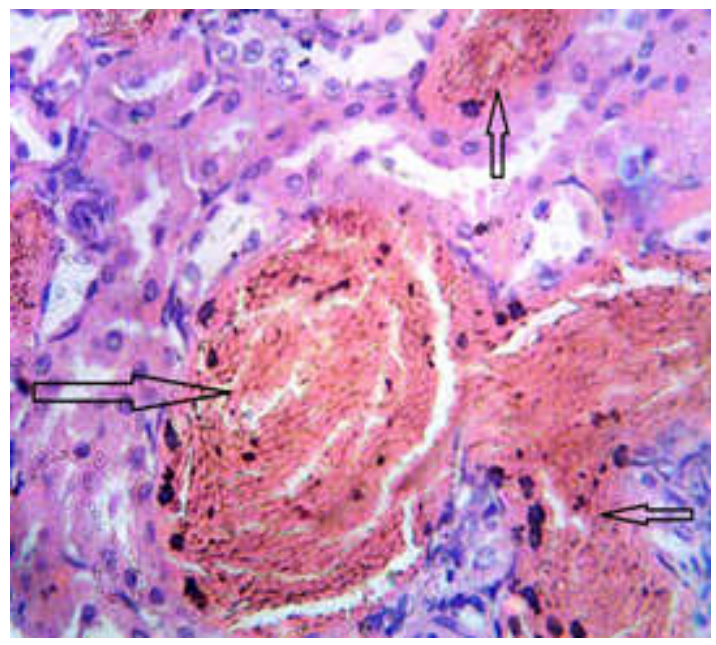

Fig 8: The kidney histopathology of experimental mice fed with C. lanatus flesh and seed juice (Group C) (Mag. X400 H\&E): Micrograph shows a linkage in the renal capsule with severe congestion of the interstitial spaces (Arrow) with mild presence inflammatory cells. The interstitial space is free from inflammatory cells.

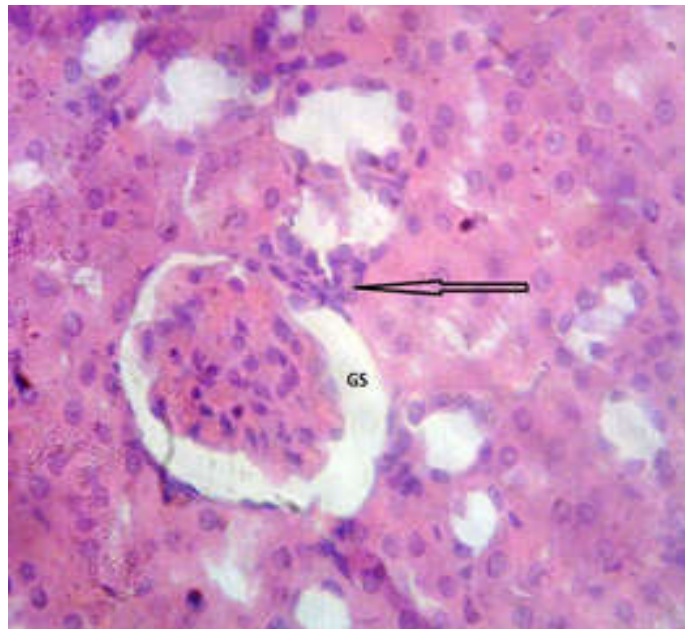

Fig 9: The kidney histopathology of experimental mice fed with C. lanatus flesh and rind juice (Group D) (Mag. X400 H\&E) Micrograph shows the renal corpuscle (arrow) with partial glomerulosclerosis (GS). The tubules are lined by regular epithelium. The interstitium is free from collections. 




Fig 10: The kidney histopathology of experimental mice fed with C. lanatus flesh, seed and rind juice (Group E) (Mag. X400 H\&E): Micrograph shows the renal tissue with marked interstitial edema (arrow) and some renal tubules (RT) within the cortex undergoing degeneration.

The liver of the animal fed with $C$. lanatus flesh juice; and C. lanatus flesh and seed juice showed periportal inflammatory cells. All plant parts and their ingredients consumed were reported to relate to the liver health because it could either be hepatoprotective or hepatotoxic (Iboi. and Agoreyo 2013). More so, hepatoprotective plants such as Citrus fruits is said to contain substances with antioxidant activities which have preventive and therapeutic effects on liver (Erhirhieand Ekene, 2013; and Iboi. and Agoreyo 2013].The kidney histopathology of the control mice showed that the renal tubule is lined by regular epithelium and the intersitum is free collection and inflammatory cell. The renal tubule of mice fed with C. lanatus flesh, seed and rind juice are lined with epithelial cell of several layers thick that have vesiculate nuclei with prominent nucleoli. The glomeruli are mildly congested; uriniferous space is mildly dilated and contain small amount of eosinphilicproteinacous material. Also, Bowman's capsule is lined by hypertrophied partial epithelial cell, edema and some renal tissue and tubule undergoing degeneration. The renal cortex of the group fed with C. lanatus flesh and rind juice exhibited variable changes. The glomerular capillaries were congested and dilated. Other renal corpuscles showed increased renal space. The intersitium showed dilated congested blood vessels. Ukoka et al., (2015) work showed congested blood vessels with glomeruli hemorrhage in the kidney following chronic consumption of Hibiscus sabdariffa.Increase in the size of proximal and distal tubules with vacuolation and shedding of the lining epithelium in the lumen were also observed. Some proximal tubules exhibited dense nuclei and deeply acidophilic cytoplasm. The renal corpuscle of the group fed with $C$. lanatus flesh juice showed glomerulus that is enclosed in the Bowman's capsule and lined by regular epithelium with the interstitium is free from collection. The kidney histopathology of the group fed with C. lanatus flesh and seed juice showed linkage in the renal capsule and congestion in the corpuscle. Oyewo et al., (2012) and Erhirhieand Ekene, (2013] reported that the kidney histology of all rats given $C$. lanatus aqueous extract were normal.

Conclusion: The result demonstrated that the administration of watermelon extracts to mice activated the immune system, immune cell in the body. The functional units of the liver and kidney tissue were not affected. Therefore, all parts of $C$. lanatus have nutritional value with hepatoprotective impact on the immune system, liver and kidney of mice.

\section{REFERENCES}

Adesanya A. O., Olaseinde O. O., Oguntayo O. D., Otulana J. O. and Adefule A. K. 2011. Effects of methanolic extract of Citrullus lanatus seed on experimentally induced prostatic hyperplasia. European Journal of Medicinal Plants. 1(4): 171-179

Ekundina V.O., Ebeye O. A., Odezi P.O. and Iwalaye O.A. 2015. Histomorphological effect of aqueous extract of water melon on the testis of adult male wistar rats. World Journal of Pharmacy and Pharmaceutical Sciences. 4(09): 1447- 1484.

El-Adawy T. A. and Taha K. M. 2001.Characteristics and composition of watermelon, pumpkin, and paprika seed oils and flours. J Agric Food Chem. 49(3): 1253 -1259.

Elujoba A. A., Odeleye O. M. and Ogunyemi C. M. 2005. Traditional Medical Development for medical and dental primary healthcare delivery system in Africa. African J. Traditional, Complementary and Alternative Medicine. 2(1): 46-61.

Erhirhie E. O. and Ekene N. E. 2013. Medicinal values on Citrullus lanatus (Watermelon): Pharmacological Review. International Journal of Research in Pharmaceutical and Biomedical Sciences.4 (4): 1305- 1312

Figueroa A., Sanchez-Gonzalez M. A., Wong A. and Arjmandi B. H. 2012. Watermelon extract 
supplementation reduces ankle blood pressure and carotid augmentation index in obese adults with prehypertension or hypertension. American Journal of Hypertension (short communication). $4 p p$.

Iboi M. E. and Agoreyo F. O. 2013. Toxicological effect of consumption of extract of jatrophatanjorensison the liver of adult wistar rats. Ijmh dev. 18(2): $69-78$.

Jiyun A., Wonhee C., Suna K. and Taeyoul H. 2011. Anti-diabetic effect of watermelon (Citrullus vulgaris Schrad) on Streptozotocin-induced diabetic mice. Food Science and Biotechnology. 20(1): $251-254$.

Kolawole T. and Dapper V. 2016. Anti-pyretic and anti-inflammatory effects of the methanolic extract of the rind of Citrullus lanatuson albino Wistar rats. Journal of Medicinal Plants Research. 10(9): 108-112.

Maria L., Javier H.B., Miguel R.D and Teresa B.M. 2008. Spectrophotometric analysis of lycopene in tomatoes and water melon. Nutrition and food science. 13: 11-13.

Motshakeri M., Ebrahimi M., Goh Y. M., Othman H. H., Hair-Bejo M. and Mohamed S. 2014. effects of brown seaweed (Sargas sumpolycystum) extracts on kidney, liver, and pancreas of Type 2 Diabetic rat model. Evidence-Based Complementary and Alternative Medicine. Hindawi Publishing Corporation. 11pp.

Oyewo O. O., Onyije F. M., Akintunde O. W. and Ashamu E. A. 2012. Effects of aqueous extract of Citrulluslanatuson thehistology of the kidney of adult wistar rats. World Applied Sciences Journal. 17 (9): 1178-1181
Sofowora A. 1993. Medicinal plants and traditional medicine in Africa. 2nd Edn. Spectrum Books Ltd., Ibadan, Nigeria, ISBN-13: 9782462195 , Pages: 289.

Sundia, 2007. Watermelon production and consumption demographics. SundraCorp. 3540pp.

Tang F. Y., Cho H. J., Pai M. H. and Chen Y. H. 2009. Concomitant supplementation of lycopene and eicosapentaenoic acid inhibits the proliferation of human colon cancer cells. $J$ Nutr. Biochem. 20: 426- 34.

Ukoha U. U., Mbagwu S. I., Ndukwe G. U. and Obiagboso C. 2015. Histological and biochemical evaluation of the kidney following chronic consumption of hibiscus sabdariffa. Advances in Biology. Hindawi Publishing Corporation. 5pp.

Wargovich M. J. 2000. Anticancer properties of fruits and vegetables. Hort Science. 35: 573575.

Yilmaz B., Sahin K., Bilen H., Bahcecioglu I. H., Bilir B., Ashraf S., Halazun K. J. and Kucuk O. 2015. Carotenoids and non-alcoholic fatty liver disease. Hepato. Biliary Surg. Nutr. 4(3): 161171

Yong S. G. and Qing H. 2015. Plants Consumption and Liver Health. Evidence-Based Complementary and Alternative Medicine. Hindawi Publishing Corporation. 10pp. 